\title{
Prioritization of Components of the System of Communications and Coordination Using the People Capability Maturity Model, Case Study: Ghom General Office of Foundation of Martyrs and Veterans Affairs
}

\author{
Amir Hossein Amirkhani \\ Associate Professor, Management Group, Payame Nour University \\ Mohammad Mahdi Najafi Shahreza
}

PhD Student, Human Resources Management, Payame Nour University

Somayeh Hassani

PhD Student, Human Resources Management, Payame Nour University

\author{
Doi:10.5901/mjss.2016.v7n3s2p71
}

\begin{abstract}
Now a day many organizations endeavor in evolution of their processes to gain more maturation. A high percent of these organizations have selected maturity models to be able to design a map of a trajectory that prepares and makes them fertile for institutional maturity. The purpose of using this model in the organization is continuous development of people skillfulness. In this research, in addition to introducing people capability maturity model, we will prioritize components of the system of communications and coordination of the general office of Foundation of Martyrs and Veterans Affair in the province of Ghom using this model. This research was descriptive-survey study in kind and instrument of data collection was researcher formulated questionnaire with 21 items. After confirmation of validity and reliability of the research data using SPSS 18 software, results show that the components of system of communications and coordination of the general office of Foundation of Martyrs and Veterans Affair in Ghom province based on the model of people capability maturity and the Friedman test are in order of priority: executive commitments, executive ability, executive activities, confirmation of implementation and evaluation. It should also be noted that the situation of the components of evaluation and executive confirmation with attention to the mean obtained is not at a desired level and there is need for implementation and institutionalization efforts for establishment of a system of communications and coordination in these sections of the mentioned organization.
\end{abstract}

Keywords: Communications and Coordination, People Capability Maturity Model, Organizational Capability, Actions for Implementation and Institutionalization

\section{Introduction}

Communications and coordination creates a primary basis for development and empowerment of working groups. This domain provides a cultural process for open sharing of information between organizational levels and in fact between dependent units. Increased flow of information provides a basis for culture of sharing and empowerment of working groups. A critical trait of this culture is that individuals can without any fear of punishment at time of expressing their concerns act in management with self-esteem.

Before people who work with each other are able to benefit from this defined process, they need to have access to necessary skills for coordination of their activities and have power over management of common dependencies. At higher maturity levels, defining processes based on qualification removes the load defined for management of dependencies by way of coordination and establishment of necessary interactions regarding roles and assignments from people's shoulders. Before access to the defined processes, skills of communications between individuals and coordination should be developed so they provide a basis for organized advancement in between work groups at higher levels.

Creation of effective communication should initiate with statement of values, policies, methods and other important organizational information to the work force. In addition to these kinds of information from above to below, there is a need for establishment of a form of lower to higher up communication by way of requesting individual opinions regarding their working conditions. Horizontal communication between units begins by way of focus on communication needs for 
performance of work (Curtis et al, 2001).

Therefore, the purpose of communications and coordination is establishment of timely communication in the organization and gaining confidence that the work force has the necessary skills for sharing of information and effective coordination of their activities. Therefore, the main issue of this research can be expressed as how can we prioritize components of the system of communications and coordination of general office of Foundation of Martyrs and Veterans Affair in the Ghom province based on indices of "people capabilities maturity model?"

\section{A Review of the Research Literature}

\subsection{Communications and Coordination}

Communications and coordination creates a preliminary basis for development and empowerment of working groups with the objective of establishment of timely communication in the organization and gaining confidence that the work force has necessary skills for sharing of information and effectively coordinating its activities.

\subsubsection{Communications}

Some definitions of communications can be mentioned as below:

1. Communications is expression of the process of creation of meaning (Dean, Bonload, 1962)

Two points are implicit here:

A- Creation

B- Meaning

2. Communications is the process of understanding and mutuality and collaboration (Nelson \& Pierson, 1983) In this definition, three points are implicit:

A- Communication is a process.

B- Communication is understanding of conceptualization.

C- Communication is sharing of information.

3. In a wide and broad definition, communication is common experiences (Farhangi, 1994).

Communication comes from the Latin term commune which means commonality (public domain).

\subsubsection{Coordination}

With design of organization units and specification of offices and internal sections, the jobs of an organization is divided between main units and the possibility for standardization of tasks and specialization of people activities is provided for. In fact, without coordination, the probability of occurrence of delay and wastage of time in performing activities, projects and programs increases and it is possible that the organization will face disability and failure. Coordination is a process during which, all sections forming a whole are combined for reaching a common goal. Coordination is realized with a set of structural and behavioral mechanisms that are used for connecting components of an organization to each other and facilitates reaching institutional objectives (Rezaian, 2007).

In the opinion of Fyol, coordination is created when first agreement and adaptability exists between various activities and sections and secondly the organization has unity in direction and goal so in this way performance of tasks is simplified and conditions for success are provided with minimal costs (Nikooeghbal, 2007).

\subsection{People Capability Maturity Model (P-CMM):}

For the first time in the early 80 's, Watts Humphrey and colleagues in the $\mathrm{IBM}^{1}$ Company introduced the main concept of the framework of the process of maturation. Humphrey with a work experience of 27 years in the IBM Company found out that the quality of a software product has direct relationship with the process used for production. Humphrey with witness of comprehensive quality management in other sections of industry aimed to install a Shewart-Deming improvement cycle (planning, performance, evaluation, action) in a software company as a method for continuous improvement of its production processes. Even though up to that time, numerous organizations had adopted advanced software technologies which were to a great extent similar to the Shewart-Deming cycle, yet, no improvement had been gained for

1 International Business Machines Corporation 
these companies. Humphrey noticed that the Shewart-Deming cycle needs installation in multiple stages so logically obstacles on the way of continuous improvement can be removed. Humphrey's unique outlook was that if organizations have the objective of creating conditions for implementation of the process of continuous improvement based on Deming's principles, they would be forced into omission of problems in a specific way.

For the first time, Crosby in his book titled "Quality is free" (Crosby, 1979) forms a clear definition of stratified structure which forms the basis of the maturity framework. Crosby's framework for quality management maturity refers to five evolutionary stages in the process of adaptability with quality programs in an organization.

This framework was coordinated by Ron Radice and colleagues under the supervision of Humphrey in the IBM Company with a software process (Radice, 1985). Crosby's main formulation was that adaptation and coordination with any new action and program in any organization occurs in five stages: the organization becomes informed of the new plan, gains more information about it, attempts to implement it in an experimental phase, executes it on the organization and reaches mastery in using it.

The main formulation of the framework of maturity in the IBM Company has been derived from Crosby's method in evolution of each process with passage from these five stages. Despite it, Humphrey noticed that in conditions that organizations implement this framework only on separate actions and technologies, they will not be successful in their process of long term adaptation with activities and programs of development of software.

Humphrey identified numerous serious obstacles in the path of long term adaptation which had to be removed. Since many of these problems were deeply related to the culture dominant on the organization, yet, he noticed that a method needs to be formulated for the entire organization to have efficiency and is not designed solely for one process.

Humphrey wished that software organizations continuously improve their software development processes and that the improvement is based on statistical information present regarding the method of implementation of every critical process. Despite it, he found out that improved software development processes will not be saved unless an organization behaves in a way that it supports them. Consequently, he designed the framework for the maturity process such that organizations would be enabled to achieve continuous procedural improvement in a matter of five years. Because of this staging, the framework is something more than a process standard which only includes a list of the best initiatives. Instead, this framework collects improved activities and programs in a staged model alongside each other so in this way it can guide the organization in its traverse through a series of cultural evolutions. Each of these stages is a building block for implementation of a complex maturity process that comes next (Radice, 1985).

The SEl${ }^{2}$ group with software evaluations, workshops and comprehensive reviews on this framework was able to transform Humphrey's maturity process to the capability maturity model software (SWCMM®) (Carnegie Mellon University). Prescription of a software for capability maturity model was published after comprehensive evaluations in 1991 and version 1.1 (Paulk, 1993) was published in January 1993. The latest version namely improved capability maturity model (CMMI) (that collects CMM centered methods for the purpose of improving engineering processes systems and software alongside each other) was first published in late 2000. The latest up to date of this software entered the market in 2006 (Chrissis, 2006).

With the passage of more than one decade from application of the P-CMM model, it became clear that this framework for maturation process can be used in managerial programs and improvement of human resources inside an organization.

People's capability maturity model is a road map and guide for recognition, design and implementation of processes related to human resources that in a continuous fashion lead to promotion of human resources capabilities. Since an organization cannot implement all the best activities in a very short time, P-CMM presents them in 5 maturity levels and 22 procedural areas. Every level of P-CMM creates a unique evolution in the organization culture and equips it with numerous powerful activities for absorption, development, organization, motivation and protection of human resources. From the view point of human resources outlooks, this model belongs to human resources strategic management models that emphasize human resources processes with consideration of strategic direction taking of the firm. The P-CMM model is a collection of actions and programs related with the domain of human capital management which is a road map for continuous improvement in human resources capabilities of an organization. In the P-CMM model, these actions and programs are referred to as human resources activities. Since the possibility of implementing the best programs related to human resources does not exist in one day, the P-CMM model defines various stages for execution of these kinds of actions. Each stage of the P-CMM model leads to a unique change in culture of an organization which is by way of equipping it with more powerful programs for the goal of absorption, growth, organization, motivation and protection of human resources. Therefore, the P-CMM model builds the foundation for a system consisting

\footnotetext{
${ }^{2}$ Software Engineering Institute
} 
of human resources activities where with movement in line with objectives, performance and fundamental needs, the organization will reach maturity (Hassani et al, 2015).

From 1995 up to now, the P-CMM model has guided programs for human resources improvement in many industries with complete success. Even though the P-CMM model is principally designed for science oriented organizations, yet, it can be used in many other organizational structures as well. The objective of the P-CMM model is improvement of human resources capability. Capability of human resources can be defined as a level of knowledge, skill and abilities related to the process of implementation of trade activities in an organization.

The P-CMM model is a description of the evolutionary enhancement process that begins from random decisions namely programs without cohesion and stability by human resources to grown sub structural programs that are adopted with the purpose of continuous evaluation of human resources capabilities. The P-CMM model is an evolutionary framework that guides organizations in the path of selection of improvement initiatives with high priority based on current maturity of the human resources programs. The main advantage of the P-CMM model is that it makes a wide range of activities related to work enhancement smaller and identifies the actions that only lead to movement towards ahead for human resources and creation of sub structural layers in the organization or entrance into the next stage. Organizations are able to only by way of staying focused on a series of actions and specific programs and their adoption in the firm structure improve their human resources permanently and achieve sustained advantages in the area of competition (Hassani et al, 2015).

\section{General Framework of Organizational Maturity Model}

PCMM includes five maturity stages that present successful principles for continuous improvement of talent, development of effective human resources and successful management of human capital. Every maturity level has been defined in a way that it determines a level of improvement capability for human resources. Five level of maturity show the high level structure of CMM.

Each maturity level is consistent of seven procedural areas. Each procedural area includes a set of objectives that if realized can prove the capability of each area in the efficiency of human resources. Procedural areas and their objectives are shown in the table below.

Table 1: Process Areas of the People CMM (Hassani et al, 2015)

\begin{tabular}{|l|l|l|}
\hline Maturity level & Focus on & Process Areas \\
\hline Optimizing & $\begin{array}{l}\text { Continuously improve and align personal, } \\
\text { workgroup, and } \\
\text { organizational capability }\end{array}$ & $\begin{array}{l}\text { Continuous Workforce Innovation } \\
\text { Organizational Performance Alignment } \\
\text { Continuous Capability Improvement }\end{array}$ \\
\hline Predictable & $\begin{array}{l}\text { Empower and integrate workforce competencies } \\
\text { and manage } \\
\text { performance quantitatively }\end{array}$ & $\begin{array}{l}\text { Mentoring } \\
\text { Organizational Capability Management } \\
\text { Quantitative Performance Management } \\
\text { Competency-Based Assets }\end{array}$ \\
\hline Eefined & $\begin{array}{l}\text { Develop workforce competencies and } \\
\text { Corkgroups, and align with business strategy and } \\
\text { Cbjectives }\end{array}$ & $\begin{array}{l}\text { Participatory Culture } \\
\text { Workgroup Development } \\
\text { Competency-Based Practices } \\
\text { Career Development } \\
\text { Competency Development }\end{array}$ \\
& $\begin{array}{l}\text { Workforce Planning } \\
\text { Competency Analysis }\end{array}$ \\
\hline Managed & $\begin{array}{l}\text { Managers take responsibility for managing and } \\
\text { developing their people }\end{array}$ & $\begin{array}{l}\text { Reward } \\
\text { Performance management } \\
\text { Work environment }\end{array}$ \\
& Communication and Coordination \\
\hline Initial & $\begin{array}{l}\text { Contradictory human resource methods } \\
\text { implemented }\end{array}$ & Organizations access to individuals \\
\hline
\end{tabular}




\section{Research Hypotheses}

The hypotheses of this research are:

Main hypothesis: The components of the system of communications and coordination of the general office of Foundation of Martyrs and Veterans Affair in the province of Ghom has desired condition based on indices of "people capability maturity model."

Minor hypotheses:

1. Executive commitments are at a desired level in the general office of Foundation of Martyrs and Veterans Affair in the province of Ghom.

2. Executive ability is at a desired level in the general office of Foundation of Martyrs and Veterans Affair in the province of Ghom.

3. Executive activities are at a desired level in the general office of Foundation of Martyrs and Veterans Affair in the province of Ghom.

4. Evaluation is performed at a desired level in the general office of Foundation of Martyrs and Veterans Affair in the province of Ghom.

5. Implementation confirmation is performed at a desired level in the general office of Foundation of Martyrs and Veterans Affair in the province of Ghom.

\section{Theoretical Framework}

Since this research is based on theory testing approach, the theoretical framework of this research is in fact the same as the maturity structure of human resources capabilities that have been mentioned in the research literature section. The process of communications and coordination has a series of objectives that describe it. To achieve these goals, the process of communications and coordination should have performed two groups of general actions in the general office of Foundation of Martyrs and Veterans Affair in the province of Ghom. Actions are being taken for implementing the system of communications and coordination and institutionalization of this process. The researcher seeks to find out that are these two groups of actions desirably performed and whether the organization in the procedural context of communications and coordination is in the second level of maturity or not and has it achieved organizational capability in the process of communications and coordination for performance of its professional activities? Otherwise, it is necessary that it performs these actions.

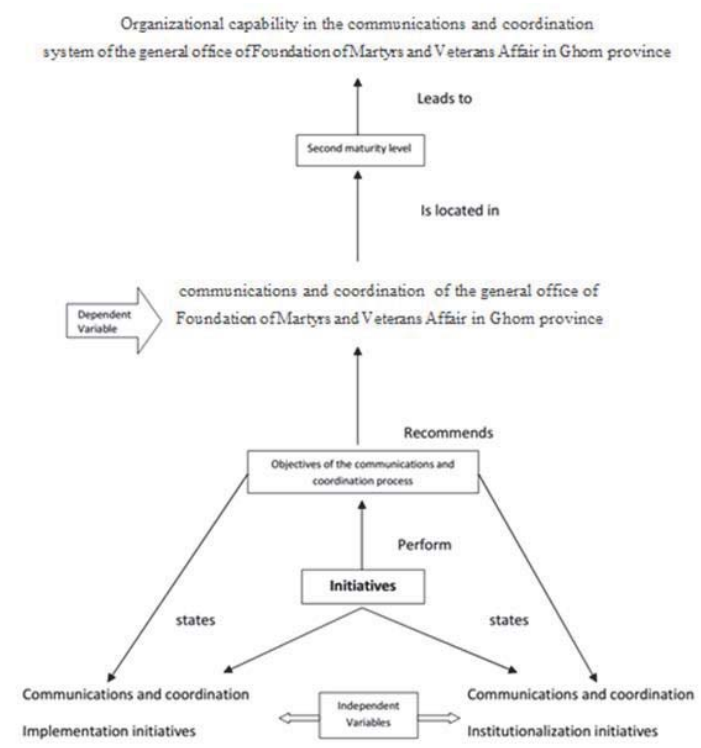

Figure 1: Research analytic model (Hassani et al, 2015) 


\section{Method of Research}

This research was descriptive-survey study in kind.

\section{Instruments of Data Collection}

For data collection, questionnaire has been used. Additionally for collection of theoretical principles and research literature, library investigation has been performed. Numerous methods exist for determination of the reliability of measuring instruments were some of the most important are content and criteria validity. Evaluation of the validity of the instrument of this research was performed using content validity. To evaluate content validity of the research instrument, questionnaire was distributed among 15 professors of management and experts who were familiar with the topic and after acquiring their opinions, revisions were implemented on the questionnaire.

For evaluation of the reliability of the questionnaire, Cronbach's alpha was calculated. The Cronbach 's alpha for all dimensions and total questionnaire was at an acceptable level. Therefore, reliability of the research instrument was confirmed.

Table 2: Cronbach's alpha coefficient for the questionnaire

\begin{tabular}{|l|c|c|c|c|c|c|c|}
\hline Kind of variable/Index & Convenient sample size & Percent & No response & Percent & Cronbach's alpha & Item number & Situation \\
\hline Executive commitments & 63 & $96.9 \%$ & 2 & $3.1 \%$ & 0.640 & 2 & Acceptable \\
\hline Executive ability & 64 & $98.5 \%$ & 1 & $1.5 \%$ & 0.825 & 3 & Acceptable \\
\hline Executive activities & 62 & $95.4 \%$ & 3 & $4.6 \%$ & 0.901 & 11 & Acceptable \\
\hline Evaluation & 65 & $100 \%$ & 0 & 0 & 0.706 & 2 & Acceptable \\
\hline Confirmation of implementation & 65 & $100 \%$ & 0 & 0 & 0.833 & 2 & Acceptable \\
\hline Communications and coordination & 60 & $92.3 \%$ & 5 & $7.7 \%$ & 0.945 & 21 & Acceptable \\
\hline
\end{tabular}

\section{Research Findings}

\subsection{Descriptive Statistics}

In this section, descriptive statistics of the demographic variables (gender, level of education and years of work) of the statistical sample has been presented in Table 3.

Table 3: Evaluation of research demographic data

\begin{tabular}{|c|c|c|c|c|}
\hline Variable & Case & Number & Percent & Cumulative percent \\
\hline \multirow{3}{*}{ Gender } & Male & 46 & 70.8 & 70.8 \\
\hline & Female & 19 & 29.2 & 100.0 \\
\hline & Total & 65 & 100.0 & \\
\hline Variable & Case & Number & Percent & Cumulative percent \\
\hline \multirow{6}{*}{ Education level } & Diploma & 7 & 10.8 & 10.8 \\
\hline & Associates of Arts & 11 & 16.9 & 27.7 \\
\hline & Bachelor's & 32 & 49.2 & 76.9 \\
\hline & Master's & 13 & 20.0 & 96.9 \\
\hline & $\mathrm{PhD}$ & 2 & 3.1 & 100.0 \\
\hline & Total & 65 & 100.0 & \\
\hline Variable & Case & Number & Percent & Cumulative percent \\
\hline \multirow{7}{*}{ Years of employment } & 1 to 5 years & 11 & 16.9 & 16.9 \\
\hline & 6-10 years & 12 & 18.5 & 35.4 \\
\hline & 11-15 years & 9 & 13.8 & 49.2 \\
\hline & $16-20$ years & 14 & 21.5 & 70.8 \\
\hline & $21-25$ years & 12 & 18.5 & 89.2 \\
\hline & More than 25 years & 7 & 10.8 & 100.0 \\
\hline & Total & 65 & 100.0 & \\
\hline
\end{tabular}


Analyses show that respondents regarding gender were $70.8 \%$ men, $29.2 \%$ women and regarding education level they included 10.8\% diploma, 16.9 percent Associates of Arts, 49.2 percent Bachelor's, 20 percent Master's and 3.1 percent PhD degrees. Regarding years of service, 49 percent of the respondents were less than 15 years and the rest at levels higher than that.

Therefore, regarding gender men and regarding level of education Bachelor's degree and regarding number of years of service 16-20 years had the highest percentages. As shown in Table 4, the indices of distribution and central tendency of the research variables are described below.

\subsection{Inferential Statistics}

The Friedman test is a nonparametric equivalent to analysis of variance with repeated measures (within groups) that is used for comparison of mean ranks between $\mathrm{K}$ variable (group). In this situation, we are faced with 5 variables that are statistically dependent. The reason is that they are measures repeated for each sample. In the Friedman test, each of the samples allocates a score to multiple groups (object or individuals or ...). In both of these tests, variables get their value from the samples, yet, the point of difference is that in analysis of variance, the measures are repeated in one sample but in the Friedman test, measures are scores given by one sample.

In the Friedman test, the $\mathrm{HO}$ hypothesis is based on equality of the mean ranks between groups. Rejection of the null hypothesis means that between the groups at least two have meaningful difference. In Table 4, mean ranks of each of the constituents and in Table 6 the main result of the test have been shown. In the table, the value for the Chi-square statistics with 5 degrees of freedom and significance level of the test (P-Value) with a value of zero can be seen which shows that $\mathrm{HO}$ hypothesis is rejected. Considering the above outputs, the final result is that components are different in the opinion of respondents. On this basis, executive commitments with a mean rank of 3.64 have the highest score and priority and evaluation with a mean rank of 2.52 has the least score and fifth priority.

Table 4: Friedman test

\begin{tabular}{|l|c|c|}
\hline Variable & \multicolumn{2}{|c|}{ Friedman Test } \\
\hline & Mean ranking & Rank \\
\hline Executive commitments & 3.64 & $\mathbf{1}$ \\
\hline Executive ability & 3.32 & $\mathbf{2}$ \\
\hline Executive activities & 2.85 & $\mathbf{3}$ \\
\hline Confirmation of implementation & 2.67 & $\mathbf{4}$ \\
\hline Evaluation & 2.52 & $\mathbf{5}$ \\
\hline
\end{tabular}

Table 5: Main test results

\begin{tabular}{|c|c|}
\hline \multicolumn{2}{|c|}{ Test Statistics } \\
\hline $\mathbf{N}$ & 65 \\
\hline Chi-Square & 24.907 \\
\hline df & 4 \\
\hline Asymp. Sig. & 0.000 \\
\hline
\end{tabular}

\section{Discussion and Conclusion}

For strengthening the role of communications, the organization should create formal procedures for expression and resolution of concerns. When concerns are expressed, they should be traced until resolution by the management so respect for the knowledge and experience created from these concerns are increased. Omission of fear of retaliation and punishment leads respect for individuals to be stabilized as important cultural ammunition. Interpersonal communication skills are necessary for maintenance of effective working relations. To have effective working groups, interpersonal problems should be addressed rapidly and meetings should be well managed to gain confidence that the time of the working group is used in the most effective form. Thus, individuals identify the dependencies of their performed work and create agreements for alignment of their activities. Individuals regulate progress in the area of these dependencies to gain confidence that necessary coordination exists in their work group. This research was performed with the purpose of prioritizing components of the system of communication and coordination in the general office of Foundation of Martyrs 
and Veterans Affair in the province of Ghom using the people capability maturation model. The results of the research showed that the main hypothesis and minor hypothesis one, two and three are confirmed and four and five are rejected.

\section{References}

\section{[In Persian]}

Farhangi, Ali Akbar. Principles of human relations. Tehran: Tehran Times Institute, 1994.

Hassani, Somayeh; Najafi Shahreza, Mohammad Mahdi; Moradi, Alireza. People capability maturity model. Tehran: Parsineh, 2015, $1^{\text {st }}$ edition.

Nikooeghbal, Ali Akbar. Selection of theories of organization and management. Tehran: Samt, 2008, $1^{\text {st }}$ edition, p 43.

Rezaian, Ali. Principles of organization and management. Tehran: Samt, 2007, 10 th edition, p 363.

[In Latin]

Curtis, Bill; William Hefley \& Sally Miler ;People Capability Maturity Model(PCMM); Version 2.0; Carnegie Mellon University;2001

Crosby, P. B. Quality Is Free: The Art of Making Quality Certain. New York: McGraw-Hill, 1979.

Chrissis, M. B., Konrad, M. \& Shrum, S. CMMI®: Guidelines for Process Integration and Prod- uct Improvement (2nd Edition). Boston: Addison-Wesley Professional, 2006.

Paulk, M. C.; Weber, C. V.; Garcia, S. M.; Chrissis, M. B.; \& Bush, M. Key Practices of the Ca- pability Maturity Model, Version 1.1 (Technical Report CMU-SEI-93-TR-25). Pittsburgh, PA: Software Engineering Institute, Carnegie Mellon University, 1993.

Radice, R. A.; Harding, J. T.; Munnis, P. E.; \& Phillips, R. W. "A Programming Process Study."IBM Systems Journal 24, 2 (1985): 79-90. www.farhangi1386.blogfa.com 